\title{
Method Study of Improving Doctor-Patient Relationship by Changing the Model of the Standardized Training of Residents in China
}

\author{
Meng-yan Sun ${ }^{1}$, Min-liang $\mathrm{Wu}^{1}$, Wei Zhang ${ }^{1}$, Ji Zhu ${ }^{1}$, Xueying Zhong ${ }^{1}$, Jian-guo Xu${ }^{1}$, \\ Hai-ying Dai ${ }^{1}$, Chunyu Xue ${ }^{1}$, and Yu-chong Wang ${ }^{1}$ \\ ${ }^{1}$ Changhai Hospital
}

July 28, 2020

\begin{abstract}
Background: The doctor-patient relationship in China is getting worse in the recent years. The aim of our study is to evaluate the effect of evidence-based medicine (EBM) on the communication between residents and patients and the doctor-patient relationship. Methods: The residents were evaluated before learning process. Then the residents in the experimental group were asked to answer a list of questions they may encounter during communication with patients before interacting with patients. Residents in the control group received traditional empirical education. Each resident was graded by a questionnaire filled by patients and senior doctors. The final test was given in the form of standardized-patient (SP) test, and the resident is graded by the SP and the examiner with the same questionnaire. Results: After studying, grades in all types of disease significantly improved in group B. Both after study and in the final test, group B performed much better than group A in all kinds of diseases. Conclusion: This is the first study to explore whether the doctor-patient relationship can be improved by EBM utilized in residents' daily communication with patients. Based on our results, the new method can benefit the residents in their long-term professional work, and can relieve the tension of relationship between doctors and patients in China.
\end{abstract}

\section{Hosted file}

manuscript.doc available at https://authorea.com/users/346743/articles/472630-method-studyof-improving-doctor-patient-relationship-by-changing-the-model-of-the-standardizedtraining-of-residents-in-china

\section{Hosted file}

table.docx available at https://authorea.com/users/346743/articles/472630-method-studyof-improving-doctor-patient-relationship-by-changing-the-model-of-the-standardizedtraining-of-residents-in-china 